\title{
A VOZ DO ESTUDANTE SOBRE A PREPARAÇÃO PARA A PROVA BRASIL
}

THE STUDENT'S VOICE ABOUT PREPARING FOR THE PROVA BRASIL

LA VOZ DEL ESTUDIANTE SOBRE LA PREPARACIÓN PARA LA PROVA BRASIL

\author{
KATH, Rosane Cristina Torres ${ }^{1}$ \\ SOUZA, Osmar de 2
}

\section{RESUMO}

Este artigo tem por objetivo sinalizar aspectos referentes ao preparo para a Prova Brasil de Língua Portuguesa, a partir das vozes de estudantes de $5^{\circ}$ ano. Nesse sentido, busca ampliar a discussão em torno desta avaliação externa e de âmbito nacional, tomando a perspectiva do estudante avaliado para visualizar efeitos decorrentes da Prova Brasil de Língua Portuguesa no contexto da sala de aula. O instrumento utilizado para gerar os dados foi a entrevista coletiva, realizada com seis estudantes de $5^{\circ}$ ano de uma escola pública estadual do Estado de Santa Catarina. Os sujeitos sinalizam que a Prova Brasil requer não apenas conteúdo, mas implica outras questões, como: modo de agir, de se portar, de compreender, à parte do que geralmente é trabalhado na escola. Nesse sentido, os sujeitos indicam que há uma preparação para este evento e destacam o simulado para auxiliar nessa questão.

Palavras-chave: Prova Brasil. Simulados. Estudantes.

\section{ABSTRACT}

This article aims to indicate aspects related to the preparation for the Prova Brasil of Portuguese Language, from the voices of 5 th year students. In this sense, it seeks to broaden the discussion around this external and national evaluation, taking the perspective of the evaluated student to visualize effects deriving from the Prova Brasil of Portuguese Language in the context of the classroom. The instrument used to generate the data for a press conference held with six 5th grade students from a state public school in the State of Santa Catarina. The subjects indicate that the Prova Brasil requires not only content, but also involves other questions, such as: how to act, how to behave, to understand, apart from what is usually worked in school.

Keywords: Prova Brasil. Simulated. Students.

\section{RESUMEN}

Este artículo tiene por objetivo señalar aspectos referentes a la preparación para la Prova Brasil de Lengua Portuguesa, a partir de las voces de estudiantes de $5^{\circ}$ año. En este sentido, busca ampliar la discusión en torno a esta evaluación externa y de ámbito nacional, tomando la perspectiva del estudiante evaluado para visualizar efectos derivados de la Prova Brasil de Lengua Portuguesa en el contexto del aula. El instrumento utilizado para generar los datos para una rueda de prensa, realizada con seis estudiantes de $5^{\circ}$ año de una escuela pública estatal del Estado de Santa Catarina. Los sujetos señalan que la Prova Brasil requiere no sólo contenido, sino que implica otras cuestiones, como: modo de actuar, de portarse, de comprender, la parte de lo que generalmente se trabaja en la escuela.

Palabras clave: Prova Brasil. Simulados. Estudiantes.

\footnotetext{
1 Universidade Regional de Blumenau - FURB - Blumenau - Santa Catarina - Brasil

2 Universidade Regional de Blumenau - FURB - Blumenau - Santa Catarina - Brasil
} 


\section{INTRODUÇÃO}

A cada dois anos, o estudante de $5^{\circ}$ ano e de $9^{\circ}$ ano do ensino fundamental é submetido à Prova Brasil, um dos componentes do sistema de avaliação da educação básica de âmbito nacional. São vários os instrumentos utilizados pelo Estado para avaliar a educação nos diferentes níveis e esferas de ensino. Neste artigo será discutida a Prova Brasil, com o objetivo de sinalizar aspectos referentes à preparação para a Prova Brasil de Língua Portuguesa, a partir das vozes de estudantes de $5^{\circ}$ ano. Buscou-se dar visibilidade ao ponto de vista de quem participa da Prova Brasil tendo que respondê-la, mas geralmente é silenciado nesse debate. Este artigo é fruto de uma pesquisa de mestrado. Os dados foram gerados por meio de entrevistas coletivas com um grupo de estudantes de $5^{\circ}$ ano que participaram da Prova Brasil ${ }^{3}$. Para análise dos dados utilizou-se de algumas contribuições de estudos sobre as avaliações em larga escala e da concepção dialógica de linguagem baseada no Círculo de Bakhtin. Na perspectiva bakhtiniana "o sentido da palavra é totalmente determinado por seu contexto" (BAKHTIN, 2004, p. 106). Ainda para o autor, a produção de sentidos acontece na enunciação, que é o produto da interação de indivíduos socialmente organizados. Partiu-se da noção de que os sujeitos da pesquisa produzem sentidos sobre a Prova Brasil na interação com o outro, através da enunciação, levando em conta que o sentido não está só no dito, mas também na entonação, nas pausas, em como a pessoa diz. $\mathrm{Na}$ análise enunciativa considera-se o "colorido expressivo" das palavras (BAKHTIN, 2003, p. 292). "Bakhtin se identificava com uma tradição hermenêutica nos estudos humanos, uma tradição que entende que o fazer científico nas ciências humanas se materializa por gestos interpretativos, por contínua atribuição de sentidos" (FARACO, 2009, p. 41).

A Prova Brasil é a "Avaliação Nacional do Rendimento Escolar" - (Anresc), sendo mais conhecida por Prova Brasil nas publicações. Esta avaliação foi criada em 2005, para integrar o sistema de avaliação da educação básica do Brasil, instituído em 1990, denominado SAEB (Sistema de Avaliação da Educação Básica). A inserção do novo exame foi "justificada em razão das limitações do plano amostral do SAEB para retratar as especificidades de municípios e escolas e apoiar com evidências a formulação de políticas visando à melhoria do ensino" (BONAMINO, 2013, p. 50).

A Prova Brasil é censitária e adentra as escolas a cada dois anos. Esta avaliação consiste num teste de desempenho aplicado aos estudantes matriculados no " $5^{\circ}$ ano ( $4^{\mathrm{a}}$ série) e $9^{\circ}$ ano ( $8^{\mathrm{a}}$ série) do Ensino Fundamental das escolas públicas que possuem, no mínimo, 20 alunos matriculados nas séries/anos avaliados" (BRASIL, 2017). O teste abrange as disciplinas de Língua Portuguesa e Matemática, com o foco respectivamente na leitura e na resolução de problemas. Além do teste, são aplicados questionários contextuais aos alunos, professores e diretores. Os aplicadores do teste

\footnotetext{
${ }^{3}$ Participaram da pesquisa estudantes de 50 ano de uma escola pública da rede estadual de ensino do Estado de Santa Catarina. Foram entrevistados seis estudantes de três 50 anos, sendo dois de cada turma. As entrevistas foram coletivas e aconteceram em momentos diferentes (dez/2015 e jun/2016), com os mesmos sujeitos. Os nomes dos sujeitos foram resguardados, adotou-se para esse artigo a identificação: "Estudante A", "Estudante B", “Estudante C", “Estudante D", “Estudante E” e "Estudante F".
} 
também preenchem um questionário sobre as condições de infraestrutura, segurança e recursos pedagógicos disponíveis (BRASIL, 2017).

Conforme portal do Instituto Nacional de Estudos e Pesquisas Educacionais Anísio Teixeira (INEP), autarquia federal vinculada ao Ministério da Educação (MEC) responsável pelo SAEB, a Prova Brasil foi criada com o objetivo de "avaliar a qualidade do ensino ministrado nas escolas das redes públicas" (BRASIL, 2017). Com a Prova Brasil se expandiu a cobertura do SAEB, permitindo que na composição do indicador educacional denominado Índice do Desenvolvimento da Educação Básica (IDEB) - que será abordado mais adiante -, a escola participante da Prova Brasil fosse colocada em evidência. Este fato, dependendo do contexto, pode ter reflexos na escola, mais diretamente na sala de aula. Desse modo, em decorrência da aplicação da Prova Brasil, da divulgação dos resultados e da composição do IDEB, as aulas das disciplinas de Língua Portuguesa e Matemática podem sofrer influência desta avaliação externa em larga escala. Segundo Dias Sobrinho "nada permanece igual e indiferente após uma avaliação" (2002, p. 39). Neste artigo, considera-se o recorte para o "antes" da avaliação.

\section{PROVA BRASIL E IDEB}

A Prova Brasil compõe um indicador educacional de ampla visibilidade, o Índice de Desenvolvimento da Educação Básica (IDEB). Criado em 2007, o IDEB reúne, em um só indicador, os resultados de dois conceitos: o fluxo escolar e a média de desempenho nas avaliações padronizadas do Inep. O cálculo do Ideb é feito a partir dos dados sobre "aprovação escolar, obtidos no Censo Escolar, e das médias de desempenho nas avaliações do Inep, o Sistema de Avaliação da Educação Básica (Saeb) - para as unidades da federação e para o país, e a Prova Brasil - para os municípios" (BRASIL, 2015). Foi a partir da Prova Brasil, sendo uma avaliação censitária e com ampla divulgação de resultados que, conforme Fernandes e Gremaud "o Brasil passa a contar com um programa de 'accountability fraca', por escolas e redes de ensino" (2009, p. 11) para o nível de ensino fundamental. O termo accountability tem sido traduzido por vários autores como, responsabilização, prestação de contas, transparência, entre outros.

Segundo informações disponíveis no portal do INEP, o IDEB não é apenas um indicador estatístico, ele surge como "condutor de política pública pela melhoria da qualidade da educação, tanto no âmbito nacional, quanto em esferas mais específicas (estaduais, municipais e escolares" (BRASIL, 2015). No discurso do Estado, o modo como o IDEB é composto possibilita não somente o "diagnóstico da situação educacional" atualizado em todas as esferas, mas também a "projeção de metas individuais intermediárias rumo ao incremento da qualidade do ensino" (BRASIL, 2015). Do ponto de vista da política pública nacional, o sistema de metas foi pensado para obter um maior comprometimento das redes e escolas objetivando a melhoria do IDEB: "Um sistema de metas pactuadas entre o Ministério da Educação e secretarias de educação de estados e municípios - serviria para aumentar a mobilização da sociedade em favor da qualidade na educação" (FERNANDES; 
GREMAUD, 2009, p. 16). O debate acerca do serviço educacional e da qualidade da educação passa a estar relacionado a este indicador.

Na voz do Estado, o IDEB "pretende ser o termômetro da qualidade da educação básica em todos os estados, municípios e escolas no Brasil" (BRASIL, 2008, p. 4). Avalia-se o fato de que nem tudo que se faz na escola em favor do ensino de qualidade se traduz no IDEB. Nessa direção, pesquisadores como Oliveira (2013, p. 94) alertam que o IDEB, "ainda que represente resultados desejáveis, não sintetiza todos os resultados esperados e desejáveis da educação contemporânea". 0 autor comenta que, "considerá-lo um indicador de qualidade é uma simplificação grosseira do que se espera da educação escolar". Além disso, Sousa salienta que "ao se enfatizar os produtos em detrimento dos processos, bem como, ao não se considerar, nas análises dos resultados das provas, os contextos de produção e reprodução dos saberes escolares, difunde-se uma noção restrita de qualidade" (2014, p. 411).

Dentro das escolas e dos sistemas de ensino, o IDEB pode criar tensões em função da "estratégia da mídia de divulgação [dos resultados], por meio de rankings, embora não oficial" (BONAMINO; SOUSA, 2012, p. 380), provocando, em alguns casos, uma busca indiscriminada pela melhor posição/nota, especialmente no ensino fundamental público, pelo caráter censitário da Prova Brasil na composição deste indicador que denomina a escola. Segundo Esquinsani, a mídia "potencializa o caráter de performatividade das avaliações de larga escala, no contexto do Estado avaliador, na medida em que torna público [...] os índices e indicadores de escolas e sistemas de ensino, focalizando a competição e o desempenho como parâmetros de qualidade" (2010, p. 137).

A utilização dos resultados do Ideb para classificação das escolas em rankings pode gerar desconforto na comunidade escolar, visto que fica o estigma da classificação de "pior" ou "melhor" escola, independente do contexto e dos fatores que podem influenciar nos resultados. Principalmente porque no ranking não há espaço para discutir o processo, mas cabe apenas o produto/resultado. A preparação para os testes, talvez, tenha sido a resposta mais imediata nas escolas, diante da recorrência de avaliações externas e em larga escala, centradas em testes de desempenho aplicados a estudantes para medir a qualidade do ensino, sendo amplamente divulgados os resultados e na maioria das vezes ranqueados pela mídia.

Conforme Horta Neto (2013), pesquisas apontam que há uma tendência em "ensinar para a prova", o que pode se tornar um problema, visto que essa avaliação externa não contempla todo o currículo escolar, mas segundo informações do portal do Inep (BRASIL, 2017), se baseia nas matrizes de referências do que é possível verificar com este tipo de instrumento avaliativo. Dessa maneira, quando há uma preocupação excessiva com os resultados do IDEB por escola, são apontados exemplos de "um possível estreitamento do currículo", com a aplicação de "simulados preparatórios" objetivando o "alcance das melhores notas do IDEB" (HORTA NETO, 2013, p. 157-158), priorizando as matrizes de referência das avaliações. Nesse sentido, Mainardes ressalta: "como o IDEB é composto com os resultados das avaliações nacionais e taxas de aprovação, as matrizes de referência dessas avaliações têm influenciado o currículo das escolas e, em consequência, as práticas pedagógicas e a 
avaliação da aprendizagem" (2013, p. 185). Nesta direção, busca-se ouvir o estudante de $5^{\circ}$ ano que foi avaliado na Prova Brasil, para apontar, com base nos enunciados dos sujeitos entrevistados no contexto investigado, aspectos que sinalizam possível influência da Prova Brasil nas aulas de Língua Portuguesa.

\section{A VOZ DO ESTUDANTE SOBRE A PREPARAÇÃO PARA A PROVA BRASIL NAS AULAS}

No contexto investigado a Prova Brasil (PB) influenciou de algum modo as aulas de Língua Portuguesa nas turmas de $5^{\circ}$ ano. São destacados nesta seção alguns excertos das entrevistas ${ }^{4}$ em que os sujeitos participantes sinalizam à influência deste teste nas aulas. Os efeitos desta avaliação compreenderam o período que antecedeu a aplicação da Prova Brasil, ao longo do ano letivo, ou seja, a partir dos enunciados dos estudantes indica-se que houve um preparo para a Prova Brasil de Língua Portuguesa e que se deu nas aulas desta disciplina. No excerto a seguir os sujeitos remetem ao simulado, que surge da conversa sobre os textos da Prova Brasil.

Excerto $1-1^{a}$ entrevista - Do diálogo sobre os textos da Prova Brasil surge o simulado.

Pesquisadora: Por exemplo, fora a Prova Brasil, vocês chegaram a fazer alguma prova antes que tinha receita de bolo?

Todos: Não.

Pesquisadora: Com bilhete de ônibus, de avião?

Estudante A: Já, eu já fiz uma, na minha outra escola.

Estudante B: Já.

Estudante C: A professora estava fazendo umas provas pra gente aprender melhor pra quando a gente fizesse a Prova Brasil.

Estudante D: treinando

Estudante E: com simulados

Estudante C: pra Prova Brasil.

Estudante F, Estudante A: É.

Pesquisadora: Vocês estavam fazendo simulados nas aulas? E todos vocês chegaram a fazer?

Todos: Sim.

${ }^{4}$ Pelo fato de adotarmos a entrevista coletiva buscou-se não isolar as falas dos sujeitos, para que o sentido da interação não se perca. Para diferenciar os excertos do restante do texto optou-se pela utilização de quadros. 
A introdução de simulados nas aulas é um dos sinais de que a Prova Brasil não foi apenas aplicada, mas influenciou neste contexto. Conforme os sujeitos os simulados são feitos nas aulas que precedem à aplicação da Prova Brasil (excerto 1). Importante destacar que o grupo de sujeitos entrevistados é composto por estudantes de três turmas e professoras diferentes (de uma mesma escola) e todos os entrevistados confirmaram essa prática. A "Estudante C", ao dizer que "a professora estava fazendo umas provas", não se referia a uma prova qualquer, mas ao simulado, como pode ser observado no transcorrer a conversa, na fala do "Estudante D" "treinando" e complementada pelo "Estudante E" "com simulados", em que os sujeitos se referem a esses testes como treinamento para a PB. A "Estudante C" utiliza a expressão "aprender melhor" para ressaltar a importância do simulado em função da PB, de modo que, com a "entonação" (BAKHTIN, 2003) se exprime um juízo de valor sobre o que está sendo dito. A estudante dá um sentido de aprendizagem ao simulado, além de atribuir um juízo de valor ao utilizar o advérbio "melhor" para se referir ao modo de aprender. O simulado aparece, nesse contexto, associado à ideia de treino e de aprendizagem.

Segundo Horta Neto (2013), a aplicação de inúmeros simulados objetivando um aumento das notas vem sendo uma estratégia adotada para preparar os estudantes para a avaliação, mas o autor ressalta que não quer dizer que o aumento das notas pressupõe uma melhora na aprendizagem. A questão da quantidade de simulados aplicado na escola investigada é abordada no excerto a seguir:

Excerto 2 - $1^{a}$ entrevista - Diálogo sobre a quantidade de simulados realizados.

Pesquisadora: Quantos simulados vocês fizeram?

Estudante C: Dois? [pergunta para Estudante D]

Estudante D: Uns três.

Estudante C, Estudante E: É dois pra três.

Estudante A: Lá na minha outra escola eu fiz um.

Pesquisadora: Tu chegaste a fazer simulado na outra escola?

Estudante A: É porque a gente já estava se preparando meses antes. A professora já estava preparando a gente pra não, não, ninguém ficar ruim, assim, no dia da prova, tipo de não conseguir. E a professora já preparou meses antes.

Pesquisadora: A professora já estava preparando meses antes? E vocês faziam simulados também? Estudante A: Fazíamos.

Pesquisadora: E quando tu vieste para essa escola?

Estudante A: Em agosto.

Pesquisadora: E aqui tu chegaste a fazer algum simulado?

Estudante A: Fiz um. 
Pesquisadora: Chegaste a fazer um? E o Estudante F?

Estudante F: Eu fiz dois pra três.

Pesquisadora: Dois pra três de Português e Matemática?

Estudante F: De Português e Matemática.

Estudante E: Eu também fiz dois pra três de Português e Matemática.

Observa-se no excerto 2 que a quantidade de simulados aplicados varia entre dois a três. Levando em conta o número de aulas de Língua Portuguesa, o número de bimestres e a quantidade de avaliações feitas pelo professor para compor a nota do boletim de cada estudante nesta disciplina, pode-se considerar que não aconteceu um número excessivo de simulados no contexto investigado. Entretanto, observa-se a ênfase dada ao verbo "preparar" no enunciado do "Estudante A" se referindo à professora da outra escola: "É porque a gente já estava se preparando meses antes. A professora já estava preparando a gente pra não, não, ninguém ficar ruim, assim, no dia da prova, tipo de não conseguir. E a professora já preparou meses antes". A ação de "preparar" sugere uma tentativa de inserir os estudantes nessa prática de produção em resposta à aplicação da Prova Brasil. Permeia um sentido de que a Prova Brasil requer não apenas conteúdo, mas implica outras questões, como: modo de agir, de se portar, de compreender, à parte do que geralmente é trabalhado na escola. Essa reflexão pode ser ampliada a partir do que anunciam os sujeitos no excerto 3 :

Excerto 3-2a entrevista - Diálogo sobre como se sentiram ao fazer a Prova Brasil.

Pesquisadora: Tem muita diferença entre fazer a Prova Brasil, como vocês fizeram no ano passado, e fazer as provas das aulas? Vocês se sentiram da mesma forma, ou muda alguma coisa?

Estudante B: Eu acho que na Prova Brasil a gente fica mais nervosa.

Estudante D, Estudante A: É! A gente fica mais.

Estudante C: É porque parece que a gente foi pressionada praticamente pra Prova Brasil, a gente tinha que estudar pra isso e tinha que fazer muita coisa. Pras provas de sala tu só precisa estudar. Mas, tipo da Prova Brasil tinha que estudar e tinha que entender tudo muito mais, três vezes mais, do que a prova de sala.

Pesquisadora: Pressionada como?

Estudante C: Tipo de ter que fazer as questões... Não sei se foi com todas as salas, mas na nossa sala ela [aplicadora] dava um tempo pra pensar e dar a resposta, se não conseguisse passava pras próximas questões e depois voltava pra ver se conseguia fazer.

Pesquisadora: O tempo é mais controlado, é isso?

Todos: É! Estudante A: É isso mesmo! 
Estudante C: Já nas provas de sala, não. Nas de sala é mais tranquilo pra fazer.

Estudante $A$ : É que às vezes a professora deixa mais tempo, porque às vezes a gente fica muito nervoso. E às vezes a professora diz: Ah! a gente espera mais um pouquinho. E aí a gente espera!

Estudante F: Eu acho que nos simulados já liberaram um pouco, aliviaram essa tensão que fica. Porque, daí já se sabe mais ou menos como vai ser a Prova, só ainda, ficamos um pouco tenso porque ela [Prova Brasil] é mais longa e porque é pessoa diferente [que aplica], mas não foi tão...

Pesquisadora: Não sentiu tanta diferença?

Estudante F: É por causa justamente que o simulado já passava aquela impressão de como ia ser a prova.

Estudante E: E também a Prova Brasil é tipo... não podia ter consulta. Já, as provas normais de vez em quando a professora deixava com consulta.

Os sujeitos compreendem que as condições reais de aplicação da Prova Brasil são diferentes das condições de produção das avaliações realizadas pelos professores, sugerindo que a Prova Brasil gera mais nervosismo. Pode-se inferir que tal fato esteja relacionado com a "responsabilização" que recai sobre o professor e por consequência incide na pressão ao estudante, mesmo que nesta política de responsabilização "as consequências são simbólicas e decorrem da divulgação de rankings de escolas e da apropriação das informações pelos pais e pela sociedade" (BONAMINO, 2013). Nessa direção, segue a afirmação da "Estudante C": "parece que a gente foi pressionada praticamente pra Prova Brasil, a gente tinha que estudar pra isso, e tinha que fazer muita coisa". Na opinião da estudante, acrescenta-se ainda que a pressão, também envolve a rigidez na aplicação da Prova Brasil, sendo controlado o "tempo pra pensar e dar resposta" (Estudante $\mathrm{C}$ ), diferente das avaliações que o professor faz. Segundo os sujeitos, existe a possibilidade do professor ampliar o tempo destinado às avaliações, devido à flexibilidade dos horários das aulas em turmas de anos iniciais, quando o professor é responsável por várias disciplinas na mesma turma. Já a padronização na aplicação do teste é uma característica das avaliações externas de larga escala, que exige uma postura diferente da sala de aula, pois nas aulas se permite um caráter mais dialógico e menos uniformizado. O "Estudante F" indica que o estranhamento com esse tipo de teste [Prova Brasil] foi amenizado com os simulados: "É por causa justamente que o simulado já passava aquela impressão de como ia ser a Prova". Nesse sentido, o sujeito dá o feedback do simulado, "eles já liberaram um pouco, aliviaram essa tensão que fica. Porque, daí já se sabe mais ou menos como vai ser a Prova, só ainda, ficamos um pouco tenso porque ela [Prova Brasil] é mais longa e porque é pessoa diferente [que aplica]" (Estudante F). Ou seja, ainda que se faça uma simulação do dia da aplicação, é o contexto que vai determinar o "sentido" (BAKHTIN, 2004) da Prova Brasil. No excerto a seguir, a questão emocional (nervosismo) surge como implicação recorrente diante de uma avaliação externa, no caso, a Prova Brasil. 
Excerto $4-2^{a}$ entrevista - Diálogo sete meses após a aplicação da PB sobre sentir-se prepararado para a prova.

Pesquisadora: E nesse ano [2016] se tivesse a PB vocês acham que deveriam se preparar pra fazer a Prova ou vocês já se sentem preparados?

Estudante A: Hum! Deveria.

Estudante B, Estudante E, Estudante F: Deveria.

\section{$[\ldots]$}

Pesquisadora: Se preparar para vocês é se preparar de que maneira?

Estudante E: Estudando.

Estudante A: Estudando, e também de alguma forma assim, que a gente tem que se preparar pra não ficar muito nervoso.

Pesquisadora: De que forma vocês acham que dá pra...?

Estudante F, Estudante D, Estudante E, Estudante A: Simulados.

Estudante C: Simulados mais dentro do conteúdo que a gente vai fazer na Prova.

Estudante D: É porque têm assuntos mais antigos que vão cair na Prova só que a gente não lembra, por isso que servem os simulados, pra gente lembrar e já estudar pra prova.

Para os sujeitos o simulado ajuda a diminuir a ansiedade do dia da aplicação da Prova Brasil, proporcionando uma aproximação com aspectos estruturais que se assemelham à prova oficial, além de relembrar assuntos já estudados; no entanto, os sujeitos ressaltam que não basta como preparo, por isso, eles enfatizam o estudo. A questão do simulado merece algumas reflexões, sugere-se ponderação na utilização. Por um lado, para ter o cuidado de não centrar as aulas de Língua Portuguesa apenas nas avaliações em larga escala e nas matrizes de referência que norteiam essas avaliações, e ainda nos simulados nestes moldes, pois o currículo escolar é mais abrangente do que o conteúdo dessas matrizes, que abordam uma parte do currículo, tendo o foco na leitura. Anuncia-se no PDE Prova Brasil que "para ser considerado competente em Língua Portuguesa, o aluno precisa dominar habilidades que o capacitem a viver em sociedade, atuando, de maneira adequada e relevante, nas mais diversas situações sociais de comunicação" (BRASIL, 2008, p. 19). Por certo, se o ensino e a aprendizagem e a avaliação da leitura forem restritos principalmente aos modelos de testes similares à Prova Brasil, sem que sejam promovidas outras experiências de leitura, comprometeria a forma como os estudantes veem os mais variados gêneros do discurso, podendo ser reduzidos a pretextos para responder itens de prova, e/ou fragmentos e exemplos do que possa cair na PB, sobrepondo-se ao sentido mais amplo do termo. Mas, por outro lado, os testes padronizados para medir o desempenho de estudantes na leitura passaram a fazer parte do contexto educacional, já na primeira etapa do ensino fundamental, pois a Prova Brasil adentra o contexto da sala de aula a cada 
dois anos. Então, se a tomarmos como um gênero do discurso que surge com "uma determinada função" (BAKHTIN, 2003, p. 266) de demanda do Estado para atender um fim específico, cabe ao professor aproximar o estudante também deste gênero, no caso com simulado, juntamente com outros gêneros do discurso que circulam socialmente.

Segundo Bauer et al. (2015), várias pesquisas confirmam que as escolas encaminham ações voltadas ao preparo e treinamento para as avaliações externas. Conforme Amaro (2014), a preparação para os testes é um dos aspectos das políticas de avaliação. $O$ autor salienta que apesar de serem parecidas, as políticas de avaliação, não adotaram características uniformes nos diversos países, mas apresentam alguns aspectos comuns: "concepções neoconservadoras de educação, foco em desempenhos, estreitamento curricular, competição entre professores e escolas, ausência da dimensão pedagógica e exacerbação da dimensão técnica, preparação para os testes" (AMARO, 2014, p. 118-119). No contexto investigado, o que se destaca nas vozes dos sujeitos é a "preparação para os testes". Pressupõe-se, ainda, que esta preparação compreenda outras questões além da aplicação de simulados, como o discurso sobre a Prova Brasil que circula na escola e na sala de aula e fica apenas na oralidade.

Outro aspecto a ser destacado é a comparação da Prova Brasil com as avaliações realizadas pelo professor de sala, abordada no excerto a seguir:

Excerto 5 - $2^{a}$ entrevista - Diálogo sobre a diferença da PB da avaliação do professor.

Pesquisadora: Vocês foram avaliados pela Prova Brasil no ano passado. Essa avaliação é ou não é diferente das provas que vocês costumam fazer?

Estudante B: Não é diferente.

Todos: Não.

Estudante B: Às vezes tem mesmas perguntas que as do livro.

Estudante E: É!

Estudante A: E aquela prova é a mesma coisa, porque ela vai falar tipo... Ah, porque querendo ou não, eles não vão perguntar uma coisa que a gente não sabe, então eles vão perguntar uma coisa que a gente já sabe pra poder botar ali na prova. Então, eles vão fazer perguntas assim... perguntas tipo que a gente... eu não sei como é que eu vou falar.

Estudante F: Ao nosso nível.

Estudante A: É isso mesmo!

Com base no excerto 5 é possível inferir que a avaliação realizada pelo professor tornou-se na opinião dos sujeitos - próxima do formato do teste da Prova Brasil, no ano da aplicação em 2015, pois todos disseram que as avaliações "não" são diferentes. A aproximação da Prova Brasil com as 
avaliações de aprendizagem feitas pelo professor surge no enunciado do "Estudante A": "E aquela prova é a mesma coisa [...] porque querendo ou não, eles não vão perguntar uma coisa que a gente não sabe, então eles vão perguntar uma coisa que a gente já sabe [...] eles vão fazer perguntas assim..." (grifo nosso), "Ao nosso nível" (Estudante F), "É isso mesmo!" (Estudante A). O estudante não leva em conta a abrangência desta avaliação em larga escala, e ainda a diversidade de escolas, de contextos e de sujeitos avaliados, pressupondo que todos os estudantes avaliados estejam num nível de desempenho esperado. Observa-se ainda, no excerto 6, como a Prova Brasil é incorporada pelos sujeitos:

Excerto 6-2ª entrevista - Diálogo sobre possíveis mudanças na aula devido à PB.

Pesquisadora: E o que mudou na escola, ou na aula, por causa da Prova Brasil? No ano que teve a Prova Brasil mudou alguma coisa ou não mudou nada?

Todos: Não, não mudou nada.

Pesquisadora: Nada?

Estudante F: Só tivemos a Prova acrescentada ali no ano, mas não mudou nada.

Estudante A: Não mudou nada, depois a gente saiu, foi pro recreio, e voltamos a nossa rotina.

A partir do excerto é possível afirmar que os sujeitos naturalizaram a $\mathrm{PB}$ e os efeitos decorrentes dela, como os simulados nas aulas das disciplinas avaliadas, e a própria tensão em torno do evento. No entanto, quando questionados a respeito da semelhança da Prova Brasil com as avaliações realizadas em 2016, os estudantes ponderam suas respostas:

Excerto 7-2a entrevista - Diálogo sobre a diferença da PB da avaliação do professor.

Pesquisadora: Mas as provas que vocês fazem hoje [6 $6^{\circ}$ ano] elas são parecidas com a Prova Brasil?

Todos: [pensativos]

Estudante B: No ano passado acho que era parecida, mas nesse ano não.

Estudante D: Sim, acho que agora não.

Estudante E: Esse ano não é.

Estudante F: Não tanto.

Estudante A: Esse ano mudou, mudou. 
Com base no excerto 7 os sujeitos afirmam que há, de fato, uma diferença entre a Prova Brasil e as avaliações de aprendizagem realizadas pelos professores, mas as semelhanças e diferenças são observadas pelos estudantes somente quando comparadas as avaliações de 2015 com as de 2016. É possível dizer que a Prova Brasil influenciou em partes a avaliação feita nas disciplinas de Língua Portuguesa e Matemática no ano de 2015, contemplaram-se provas com questões objetivas e o desempenho em leitura e resolução de problemas (baseado na Matriz de Referência da PB). Há sinais de que esse processo não esteja muito claro ao estudante, conforme pode ser observado no enunciado do "Estudante B": "No ano passado acho que era parecida, mas nesse ano não". Apesar disso, não se pode afirmar que em 2015 foram privilegiados somente simulados ou provas objetivas com foco na leitura (cf. excerto 3), mas é possível dizer que a semelhança com a Prova Brasil incidiu mais no ano de 2015 que no ano seguinte. Essa questão é ampliada no excerto 7:

Excerto 8-2 entrevista - Diálogo sobre provas objetivas no $6^{\circ}$ ano.

Pesquisadora: Vocês costumam fazer provas com questões objetivas [assinalar]?

Estudante D: Não, só às vezes.

Estudante B: Na nossa sala é às vezes.

Estudante E, Estudante F: Às vezes.

Estudante A: Na nossa sala é mais de Geografia.

Estudante E: Geografia e História.

Pesquisadora: Só em algumas disciplinas, então?

Estudante A: Porque em Português é mais de responder, responda tal ou complete tal..., mais assim.

Pesquisadora: E, essas provas têm gabarito também, ou não?

Todos: Não.

Pesquisadora: Na Prova Brasil tinha?

Todos: Sim.

O que os estudantes sugerem no excerto 8 é que de um ano para o outro saem de foco as questões objetivas nas disciplinas de Língua Portuguesa e Matemática, diferente do que aconteceu nestas disciplinas nas turmas de $5^{\circ}$ anos, quando foram avaliadas na Prova Brasil. Observa-se ainda outro aspecto referente à influência da Prova Brasil nas aulas, sendo indicado pela "Estudante C" no excerto 9:

Excerto 9-2a entrevista - Diálogo sobre a interferência da Prova Brasil nas aulas. 
[‥]

Pesquisadora: Então, a Prova Brasil interfere nas aulas?

Estudante C: Porque eu acho que no ano passado eu lembro que eles faziam alguns conteúdos novos para uns e para outros um conteúdo diferente. Então, por exemplo, eles passavam conteúdo adiante do que tinha na Prova para uma turma e para outra nem tanto. Então acabava sendo um pouco difícil assim.

Neste caso, a estudante toma a Prova Brasil como parâmetro curricular ao mencionar que "eles passavam conteúdo adiante do que tinha na Prova para uma turma e para outra nem tanto". Conforme o portal do Inep as matrizes de referência não englobam todo o currículo escolar, por isso não podem ser confundidas com as matrizes curriculares. "Também não podem ser confundidas com procedimentos, estratégias de ensino ou orientações metodológicas, pois é um recorte sobre os conteúdos curriculares estabelecidos para determinada etapa ou ciclo escolar" (BRASIL, 2017). Segundo Horta Neto (2013), pode haver um "estreitamento do currículo" quando se privilegiam nas salas de aula somente os conteúdos das áreas de Língua Portuguesa e de Matemática que serão avaliados no Saeb. Ressalta-se que não é possível dizer se houve um estreitamento curricular no contexto investigado, mas apenas o sujeito parte da Prova Brasil para sinalizar que os conteúdos trabalhados nas três turmas de $5^{\circ}$ ano não foram padronizados por este teste.

Para finalizar, o período que compreende a influência da Prova Brasil no contexto investigado é demarcado pelos sujeitos no excerto 10:

Excerto $10-2^{a}$ entrevista - Sobre a possibilidade de um diálogo pós-prova na escola.

Pesquisadora: No final de 2015 vocês fizeram a Prova Brasil, depois da aplicação da prova alguém da escola conversou com vocês sobre a prova?

Todos: Não.

Pesquisadora: Algum professor perguntou como foi?

Todos: Não

Pesquisadora: Nem a direção da escola? Nem a coordenação?

Todos: Não. Estudante A: Ninguém.

Pesquisadora: Foi feita a Prova e não se tocou mais nesse assunto?

Estudante A: É, e daí nós fomos pra sala e continuamos a estudar.

Pesquisadora: Continuaram a matéria e não foi mais tocado no assunto da prova até o final do ano?

Todos: Sim. 
Os sujeitos apontam que a influência da Prova Brasil nas aulas de Língua Portuguesa foi pontual, compreendeu o ano de 2015 num período que antecedeu a aplicação da prova envolvendo a preparação com simulados para o dia da prova oficial. Observa-se que após o momento da aplicação da Prova Brasil houve um silenciamento sobre o assunto, destoando da ênfase que foi dada à prova até aquele momento. Dito de outra maneira, a Prova Brasil sai de foco nas aulas logo após a sua aplicação.

Nas vozes dos sujeitos "ecoam" (BAKHTIN, 2003) vozes de discursos de importância da Prova Brasil, nesse sentido, a "atitude responsiva ativa" dos sujeitos está nos enunciados que apontam para a relevância, preparo e aceitação deste evento.

\section{CONSIDERAÇÕES FINAIS}

A Prova Brasil de Língua Portuguesa mede a proficiência leitora. Tem-se o entendimento que a aplicação da prova no $5^{\circ}$ ano avalia o desempenho dos estudantes ao final da primeira etapa do ensino fundamental, ou seja, os resultados podem refletir o trabalho realizado durante toda esta etapa.

Destaca-se na voz dos sujeitos que há necessidade de se preparar para a Prova Brasil, nesse contexto, eles indicam o simulado. Talvez esse tipo de teste tenha chamado mais a atenção dos sujeitos, dentre outras ações da escola voltadas à leitura, por ser o exemplo prático e mais próximo da situação esperada no dia da aplicação da prova. É possível dizer que algumas ações ligadas ao preparo para a Prova Brasil refletiram de algum modo, na opinião dos sujeitos sobre a similaridade entre esta avaliação externa e a avaliação realizada pelo professor. Mas compreende-se ainda, que foram realizadas outras e diferentes avaliações de aprendizagem durante o ano letivo de 2015.

No contexto investigado, a Prova Brasil perdeu o foco logo depois de sua aplicação, mas durante o ano letivo, no período que antecedeu a prova houve uma preocupação com sua aplicação, e que resultou num preparo. Pressupõe-se, ainda, que esta preparação compreenda outras questões além da aplicação de simulados, como o discurso sobre a Prova Brasil que circula na escola e na sala de aula e fica apenas na oralidade.

Dessa forma, é preciso conhecer, também, a perspectiva do estudante avaliado e considerar que um instrumento de avaliação externa pode gerar ansiedade e estranhamentos para os sujeitos envolvidos no interior da escola. Os sujeitos sinalizam que a Prova Brasil requer não apenas conteúdo, mas implica outras questões, como: modo de agir, de se portar, de compreender, à parte do que geralmente é trabalhado na escola. Nesse sentido, os sujeitos indicam que há uma preparação para este evento e destacam o simulado para auxiliar nessa questão.

A Prova Brasil é um teste padronizado de âmbito nacional, possui aplicação e aspectos estruturais peculiares. Esta avaliação externa em larga escala, baseada em testes de desempenho como instrumento principal do sistema de avaliação da educação básica para verificação da qualidade 
do ensino público é um gênero do discurso que passou a fazer parte do "calendário escolar", estando presente nas aulas a cada dois anos. Consequentemente, a aplicação da Prova Brasil influencia mais diretamente as aulas das disciplinas avaliadas, sendo um gênero a ser discutido pelos professores e estudantes, de maneira que possam compreender este tipo de teste e suas implicações dentro e fora da sala de aula.

\section{REFERÊNCIAS}

1. AMARO, Ivan. Avaliar ou examinar a escola? Performatividade, regulação e intensificação do trabalho docente. Impulso, Piracicaba, v. 24, n. 61, p. 109-127, set./dez. 2014. Disponível em: http://dx.doi.org/10.15600/2236-9767/impulso.v24n61p109-127. Acesso em: 6 jul. 2016.

2. BAKHTIN, Mikhail. Estética da criação verbal. Trad. Paulo Bezerra. 4. ed. São Paulo: Martins Fontes, 2003. ; (VOLOCHINOV). Marxismo e filosofia da linguagem: problemas fundamentais do Método Sociológico na Ciência da Linguagem. 13 ed. São Paulo: Hucitec, 2004.

4. BAUER, Adriana. et al. Avaliação em larga escala em municípios brasileiros: o que dizem os números? Estudos em Avaliação Educacional, São Paulo, v. 26, n. 62, p. 326-352, maio/ago. 2015. Disponível em: http://dx.doi.org/10.18222/eae266203207 Acesso em: 2 jul. 2016.

5. BONAMINO, Alicia Catalano de. Avaliação educacional no Brasil 25 anos depois: onde estamos? In: BAUER, A.; GATTI, B. A. (Orgs.). Vinte e cinco anos de avaliação de sistemas educacionais no Brasil: implicações nas redes de ensino, no currículo e na formação de professores. V. 2. Florianópolis: Insular, 2013.

6. BONAMINO, Alicia Catalano de; SOUSA, Sandra Zákia. Três gerações de avaliação da educação básica no Brasil: interfaces com o currículo da/na escola. Educação \& Pesquisa, São Paulo, v. 38, n. 2, p. 373-388, abr./jun. 2012. Disponível em: http://www.scielo.br/pdf/ep/v38n2/aopep633.pdf. Acesso em: 15 maio 2015.

7. BRASIL. Ministério da Educação. PDE: Plano de Desenvolvimento da Educação: Prova Brasil: ensino fundamental: matrizes de referência, tópicos e descritores. Brasília: MEC, SEB; Inep, 2008.

8. Ministério da Educação. Anresc (Prova Brasil) / Aneb. 2017. Disponível em: http://portal.inep.gov.br/web/guest/educacao-basica/saeb/sobre-a-anresc-prova-brasil-aneb. Acesso em: 20 out. 2017. 
Ministério da Educação. Metas educacionais. 2015. Disponível em: http://portal.inep.gov.br/web/guest/metas-educacionais. Acesso em: 20 out. 2017.

Ministério da Educação. Perguntas frequentes. 2017. Disponível em: http://portal.inep.gov.br/web/guest/educacao-basica/saeb/perguntas-frequentes. Acesso em: 20 out. 2017.

SAEB.

2017.

Disponível

em: http://portal.inep.gov.br/web/guest/educacao-basica/saeb. Acesso em: 20 out. 2017.

12. DIAS SOBRINHO, José. Educação e avaliação: técnica e ética. In: DIAS SOBRINHO, J.; RISTOFF, D. I. (Orgs). Avaliação democrática: para uma universidade cidadã. Florianópolis: Insular, 2002.

13. ESQUINSANI, Rosimar Serena Siqueira. Performatividade e educação: a política das avaliações em larga escala e a apropriação da mídia. Práxis Educativa, Ponta Grossa, v.5, n. 2, p. 131-137, jul./dez. 2010. Disponível em: www.revistas2.uepg.br/index.php/praxiseducativa/article/download/1023/1390 Acesso em: 10 fev. 2013.

14. FERNANDES, Reynaldo; GREMAUD, Amaury. Qualidade da educação: avaliação, indicadores e metas. 2009. Disponível em: http://www.cps.fgv.br/ibrecps/rede/seminario/reynaldo_paper.pdf, Acesso em: 5 jul. 2015.

15. HORTA NETO, João Luiz. IDEB: limitações e usos do indicador. In: BAUER, A.; GATTI, B. A.; TAVARES, M. R. (Orgs.). Vinte e cinco anos de avaliação de sistemas educacionais no Brasil: origens e pressupostos. V. 1. Florianópolis: Insular, 2013.

16. MAINARDES, Jefferson. As relações entre currículo, pedagogia e avaliação no contexto das avaliações de sistemas educacionais. In: BAUER, A.; GATTI, B. A. (Orgs.). Vinte e cinco anos de avaliação de sistemas educacionais no Brasil: implicações nas redes de ensino, no currículo e na formação de professores. V. 2. Florianópolis: Insular, 2013.

OLIVEIRA, Romualdo Portela de. A utilização de indicadores de qualidade na unidade escolar ou porque o IDEB é insuficiente. In: BAUER, A.; GATTI, Bernadete A. (Orgs.). Vinte e cinco anos de avaliação de sistemas educacionais no Brasil: implicações nas redes de ensino, no currículo e na formação de professores. V. 2. Florianópolis: Insular, 2013.

SOUSA, Sandra Zákia. Concepções de qualidade da educação básica forjadas por meio de avaliações em larga escala. Avaliação, Campinas; Sorocaba, SP, v. 19, n. 2, p. 407-420, jul. 2014. Disponível em: http://www.scielo.br/pdf/aval/v19n2/a08v19n2.pdf. Acesso em: 10 fev. 2017. 


\section{Rosane Cristina Torres Kath}

Mestre em Educação pelo PPGE FURB; Departamento e área da Educação; Vinculada ao projeto de pesquisa: Avaliações em larga escala no Brasil.

\section{Osmar de Souza}

Professor Colaborador do PPGE FURB; Departamento e área da Educação; Coordenador do projeto de pesquisa: Avaliações em larga escala no Brasil.

\section{Como citar este documento:}

KATH, Rosane Cristina Torres; SOUZA, Osmar de. A voz do estudante sobre a preparação para a prova Brasil. Reflexão e Ação, Santa Cruz do Sul, v. 27, n. 1, dez. 2018. ISSN 1982-9949. Disponível em: $\quad$ <https://online.unisc.br/seer/index.php/reflex/article/view/11976>. Acesso em: doi:https://doi.org/10.17058/rea.v27i1.11976. 